\title{
Title: Mechanism and Dynamics of Fast Redox Cycling in Cerium Oxide Nanoparticles at High Oxidant Concentration
}

Vladyslav Seminko ${ }^{+*}$, Pavel Maksimchuk ${ }^{\dagger}$, Ganna Grygorova ${ }^{\dagger}$, Elena Okrushko ${ }^{\dagger}$,

Oleg Avrunin $¥$, Valerii Semenets ${ }^{\ddagger}$, Yuri Malyukin ${ }^{\dagger}$

$\dagger$ Institute for Scintillation Materials, National Academy of Sciences of Ukraine, 61072, 60 Nauky Ave., Kharkiv, Ukraine.

$¥$ Kharkiv National University of Radioelectronics, 14 Nauky Ave., Kharkiv, Ukraine

\section{Characterization of the samples}

The solid phase of colloidal solutions of cerium oxide $\left(\mathrm{CeO}_{2-\mathrm{x}}\right)$ nanocrystals obtained by the method described above was characterized using the methods of $\mathrm{X}$ ray diffraction (XRD) and transmission electron microscopy (TEM). According to TEM data the average sizes of nanoparticles were about $2 \mathrm{~nm}$ and $10 \mathrm{~nm}$ with narrow size dispersion (Figure $\mathrm{S} 1$ ). XRD patterns of obtained $\mathrm{CeO}_{2-\mathrm{x}}$ nanocrystals are shown in the Figure S2. The structure of the samples corresponds to JCPDS card No.340394, so the nanocrystals are characterized by FCC fluorite-type lattice and formation of any additional phases can be excluded. Also, despite the possible presence of vacancies and other structural defects, the positions of the XRD peaks and so, the values of the lattice parameters for $2 \mathrm{~nm}$ and $10 \mathrm{~nm}$ nanoceria correspond to the values determined previously for the bulk ceria $(\approx 5.41 \AA)$. At the same time, sufficient broadening of the XRD peaks for $2 \mathrm{~nm}$ nanoparticles is observed that can be relied to higher structural imperfection of the $2 \mathrm{~nm}$ samples.

The results of DLS measurements of hydrodynamic diameter $\left(\mathrm{d}_{\mathrm{h}}\right)$, polydispersity index $(\mathrm{PdI})$, zeta potential ( $\zeta$-potential), and conductivity of $\mathrm{CeO}_{2}$ 
colloidal solutions $(0.5 \mathrm{~g} / \mathrm{L})$ are shown in the Table S1 along with the data on the density and specific surface area of nanoparticles. The density of the solid phase was determined using the pycnometric measurements after evaporation of the solutions and drying at $100{ }^{\circ} \mathrm{C}$ until constant mass. The specific surface area of nanoparticles was calculated using the average sizes determined from TEM.

FTIR spectrum of as-prepared $2 \mathrm{~nm}$ nanoceria is shown in Figure S3. The bands obtained at 745, 615 and $540 \mathrm{~cm}-1$ correspond to Ce-O stretching mode. Two bands at 1390 and $1585 \mathrm{~cm}^{-1}$ belong to symmetrical and asymmetrical valence vibrations of the carboxylate groups. Two peaks at 1078 and $1270 \mathrm{~cm}^{-1}$ correspond to C-O citrate stretching bands. Two sharp peaks at 2920 and $2860 \mathrm{~cm}^{-1}$ were assigned to the asymmetric vibrations and asymmetric vibrations of $\mathrm{C}-\mathrm{H}$ groups for hydrocarbon chain, respectively, indicating the presence of the citrate ligands on the surface of the nanoparticles. A broad band in the range of $3200-3500 \mathrm{~cm}^{-1}$ and a weak sharp band at $1665 \mathrm{~cm}-1$ are characteristic for stretching vibrations and bending vibration of the $\mathrm{O}-\mathrm{H}$ groups, indicating that the $\mathrm{CeO}_{2}$ NPs contain hydroxyl groups or $\mathrm{H}_{2} \mathrm{O}$ on their surfaces. As $\mathrm{CeO}_{2} \mathrm{NPs}$ are synthesized in aqueous solution, their surface is capped with a large number of hydroxyl groups either chemically bonded or physically adsorbed to the surface.

Table S1. DLS measurements of hydrodynamic diameter $\left(d_{h}\right)$, polydispersity index (PdI), zeta potential ( $\zeta$-potential), conductivity of $\mathrm{CeO}_{2}$ colloidal solutions $(0.5 \mathrm{~g} / \mathrm{L})$.

\begin{tabular}{|l|l|l|}
\hline & $2 \mathrm{~nm}$ nanoceria & $10 \mathrm{~nm}$ nanoceria \\
\hline $\mathrm{pH}$ & 7.30 & 7.40 \\
\hline $\mathrm{d}_{\mathrm{h}}(\mathrm{nm})$ & $9.0 \pm 0.4$ & $64.0 \pm 0.3$ \\
\hline $\mathrm{PdI}$ & 0.217 & 0.164 \\
\hline$\zeta$-potential $(\mathrm{mV})$ & $-19.21 \pm 0.5$ & $-21.15 \pm 0.5$ \\
\hline Conductivity $(\mu \mathrm{S})$ & 1550 & 1486 \\
\hline Density $\left(\mathrm{g} / \mathrm{cm}^{3}\right)$ & 2.55 & 2.55 \\
\hline
\end{tabular}




\begin{tabular}{|l|l|l|}
\hline Specific surface area, $\mathrm{m}^{2} / \mathrm{g}$ & 1176 & 235 \\
\hline
\end{tabular}
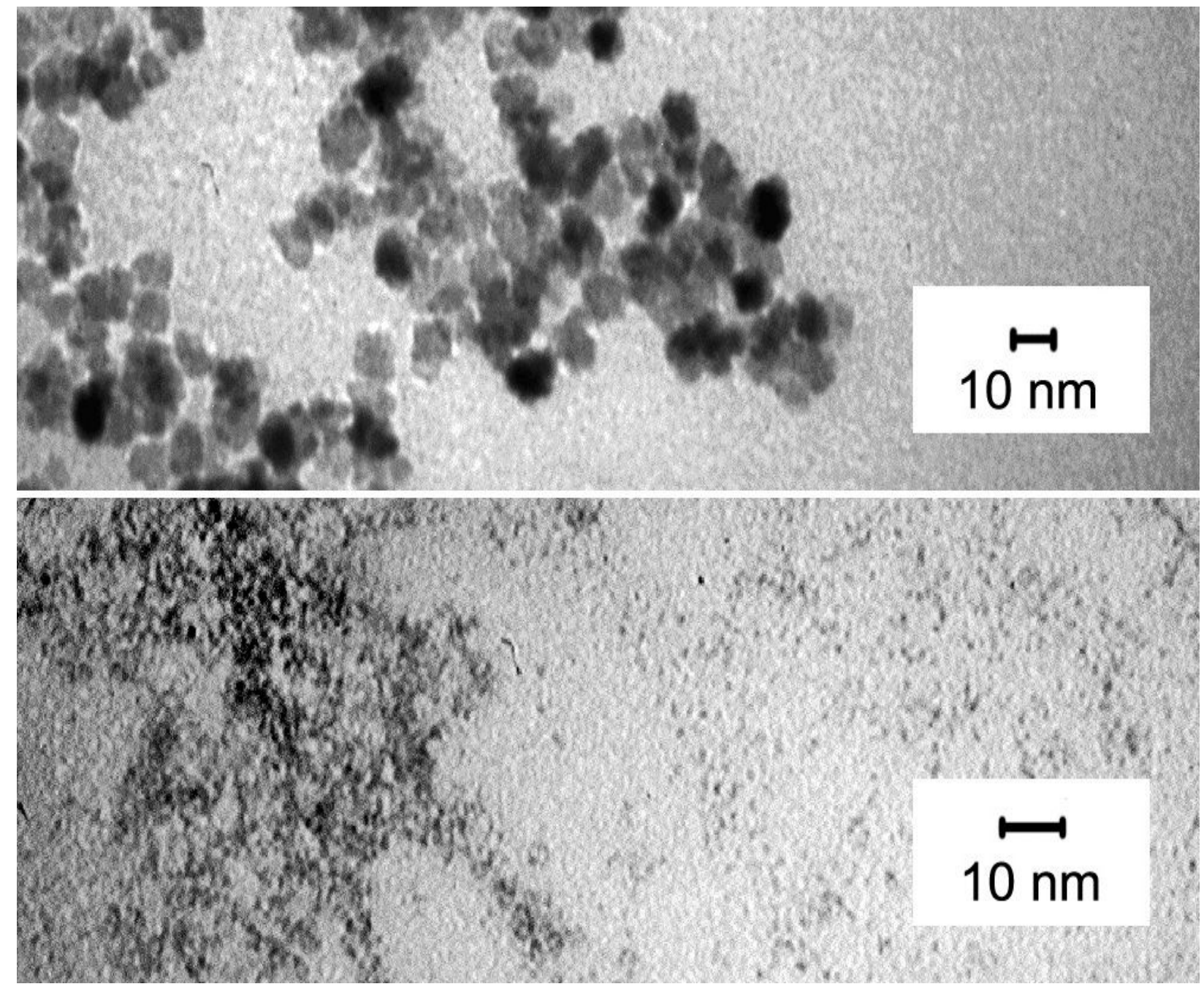

Figure S1.TEM of tested nanoceria specimens as obtained. 


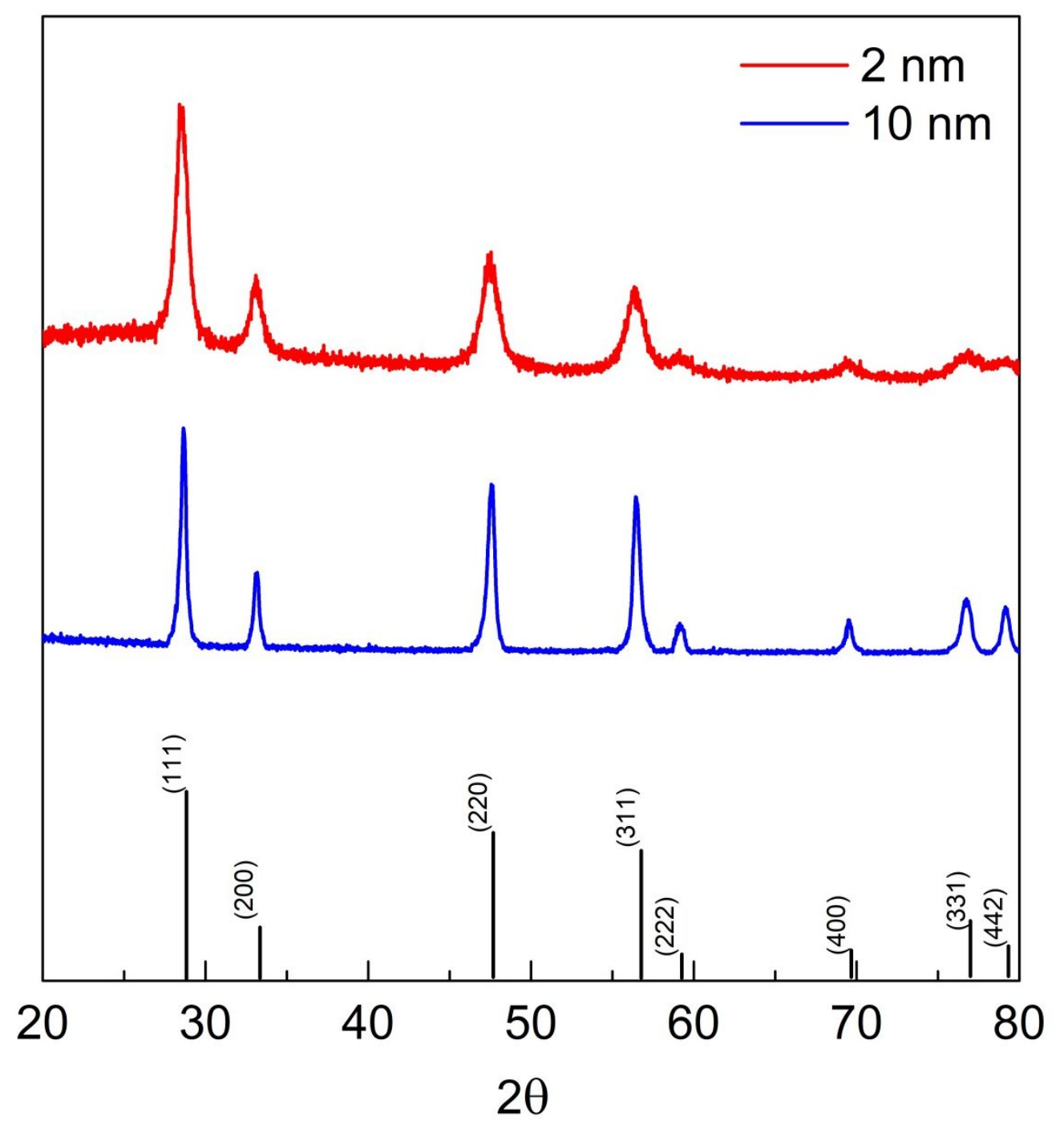

Figure S2. XRD of $2 \mathrm{~nm}$ and $10 \mathrm{~nm}$ nanoceria. 


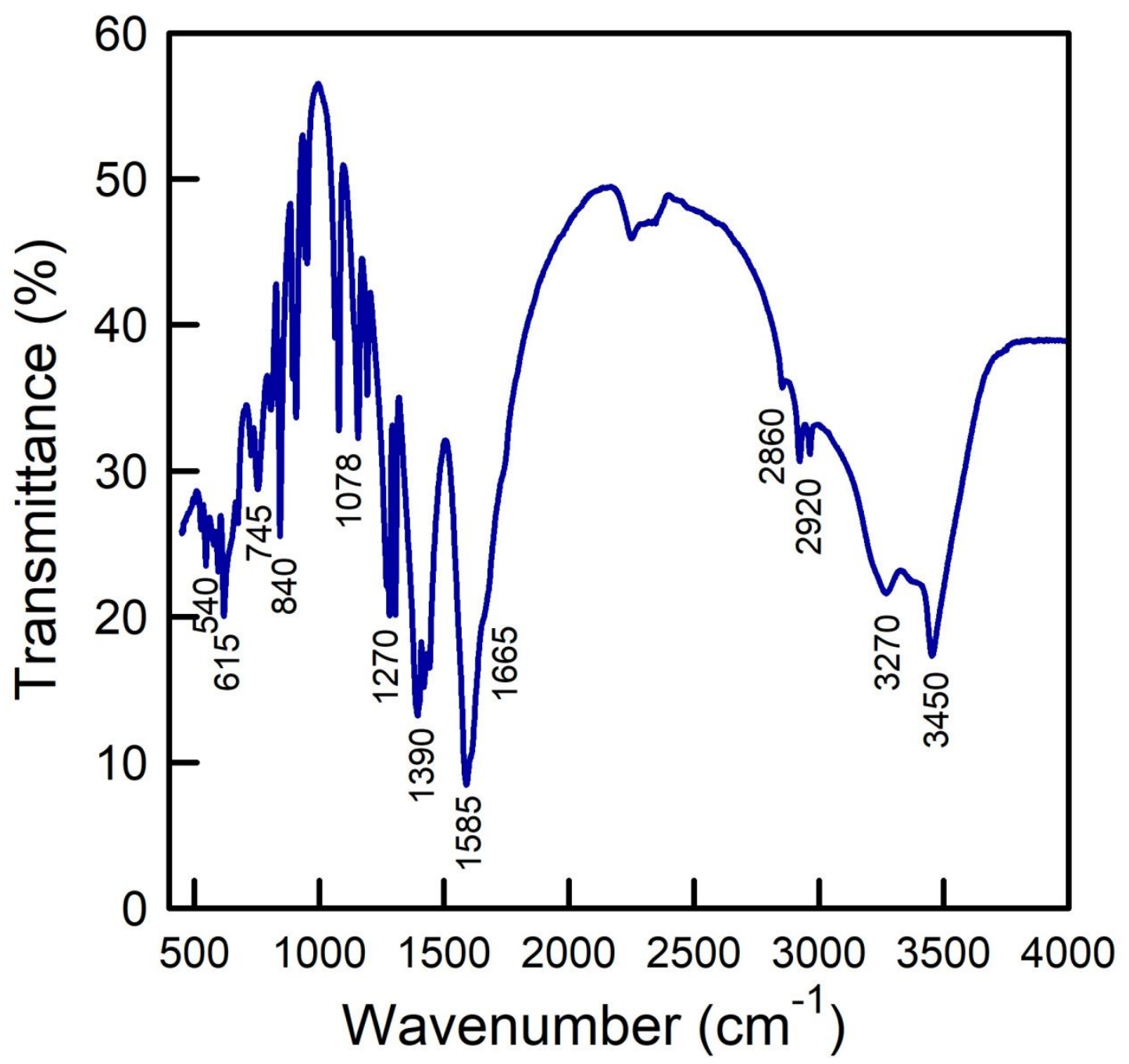

Figure S3. FTIR spectra of $2 \mathrm{~nm}$ nanoceria. 

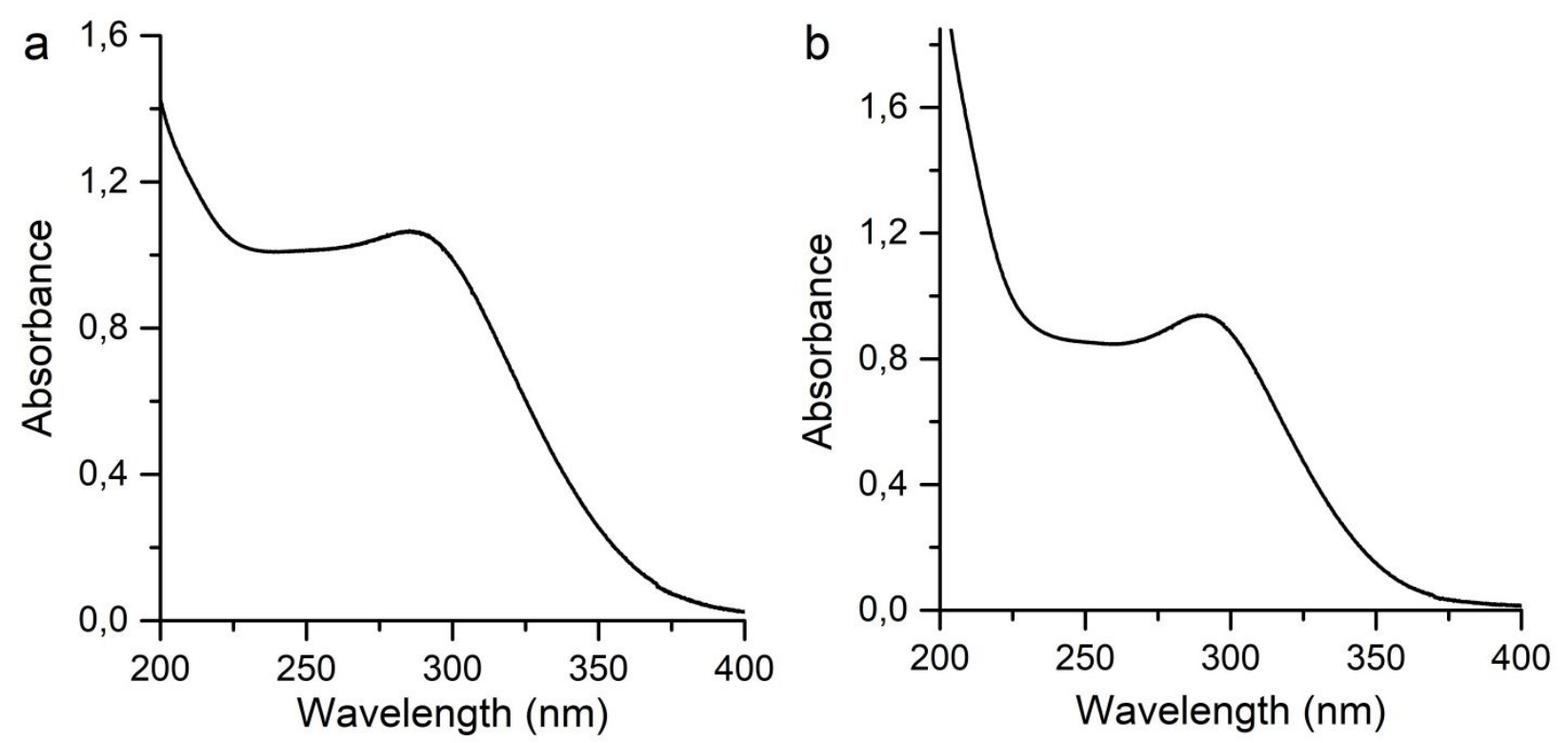

Figure S4. Absorption spectra of $2 \mathrm{~nm}$ (a) and $10 \mathrm{~nm}$ (b) nanoceria. 


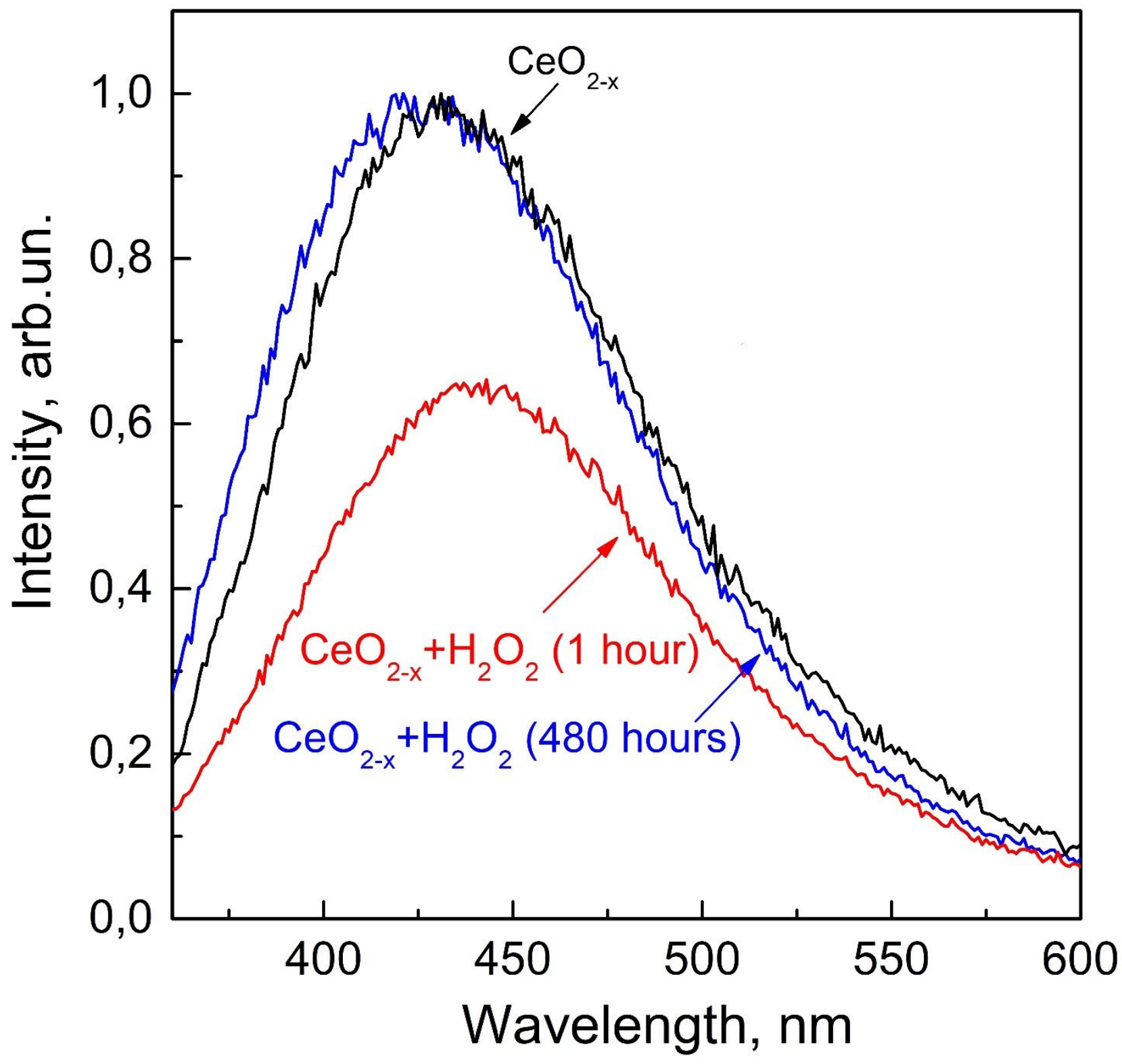

Figure S5. Luminescence spectra of nanoceria $(2 \mathrm{~nm})$ different times after addition of hydrogen peroxide $(\mathrm{C}=60 \mathrm{mM})$. 